\title{
Juvenile distal spinal muscular atrophy of upper extremities in Chinese males: a single fibre electromyographic study of arms and legs
}

\author{
Y W Chan, R Kay, M S Schwartz
}

\begin{abstract}
Single fibre electromyography (SFEMG) was performed on six young Chinese males with distal spinal muscular atrophy of the upper extremities. Abnormal SFEMG findings of increased fibre density, jitter and blocking were recorded over both arms and legs in all patients, suggesting a more generalised disturbance than would appear clinically.
\end{abstract}

There have been a number of reports of juvenile distal spinal muscular atrophy (JDSMA) affecting the arms, from Asia including Japan, ${ }^{1-3}$ India, ${ }^{45}$ and Sri Lanka. ${ }^{6} \mathrm{~A}$ report from Malaysia ${ }^{7}$ included seven Chinese patients. In previous reports, electromyographic (EMG) studies of the legs in these patients were rarely performed ${ }^{48}$ and quantitative measurement with single fibre electromyography (SFEMG) was not carried out.

We report a further six Chinese patients with JDSMA from Hong Kong to determine the extent of the neurological disturbance by SFEMG in the arms and legs of all the patients.

\section{Materials and methods}

Six Hong Kong Chinese men whose ages ranged from 16 to 37 years (average 25 years) were studied. All had weakness and wasting of the hand and forearm muscles affecting one upper extremity initially; the left in four and the right in two patients. The age of onset ranged from 15 to 27 years (average 20 years) and the duration of illness was from one to 10 years. The opposite upper extremity was also affected to a lesser degree in five patients at six months to five years after onset of initial symptoms. There was no progression of symptoms after an average of 2.3 years in five patients. Two patients had cold paresis of the affected hand. Five had no weakness in the legs and one had mild difficulty in toe walking on the left. None had a positive family history of neuromuscular disorders. One patient gave a past history of neck injury sustained while ice-skating.

Neurological examination revealed normal or hypoactive reflexes in the involved upper extremity. There were no sensory deficits. Fasciculations were noted in four patients and action tremor of the hands in three patients. Weakness and wasting were confined to small hand muscles and forearm flexors and extensors. One patient had hypertrophy of the abductor pollicis brevis muscle of the affected hand in spite of the marked weakness of this muscle. The creatine kinase (CK) level was slightly elevated in two patients. Myelography performed in three patients was normal.

\section{Electrophysiological studies}

All patients had motor and sensory nerve conduction studies, as well as concentric needle EMG of the arms and legs. The SFEMG was performed with a Medelec single fibre electrode (SF 25) and a Medelec MS92A or MS6 Medelec machine using a bandwidth of $500 \mathrm{~Hz}-10 \mathrm{~Hz}$. Fibre density measurement of the right and left extensor digitorum communis and tibialis anterior muscles were taken. The fibre density in SFEMG is the mean number of single muscle fibre action potentials recorded within the uptake area of an SFEMG electrode in approximately twenty different positions. ${ }^{9}$ In normal subjects the fibre densities in our laboratory of extensor digitorum communis and tibialis anterior muscles are less than 1.8.

\section{Results}

The motor and sensory conduction studies were normal. Small or absent motor responses were, however, obtained on motor conduction from very atrophied muscles over the hands. Routine concentric needle EMG of the arms showed chronic partial denervation of the affected muscles and to a lesser degree of the muscles on the opposite side. In the legs, only rare polyphasic units were recorded, but none of the muscles showed denervation.

Fibre density measurements were abnormal in 23 of 24 muscles on which SFEMG was performed (table and figure). The highest fibre density for the affected arm was $5 \cdot 1$ (case 5 ) and for the less affected arm was 4.5 (case 6 ). There was, however, no difference between the average fibre density of the affected and the less affected arm. Although asymptomatic, the fibre density measurements in the legs were abnormal except in the right tibialis 
Table SFEMG-Fibre densities of the extensor digitorum communis and tibialis anterior muscles *

\begin{tabular}{|c|c|c|c|c|}
\hline \multirow[b]{2}{*}{ Case } & \multicolumn{2}{|c|}{ Extensor digitorum communis } & \multicolumn{2}{|c|}{ Tibialis anterior } \\
\hline & Affected arm & Less affected arm & Right leg & Left leg \\
\hline $\begin{array}{l}1 \\
2 \\
3 \\
4 \\
5 \\
6 \\
\text { Average fibre density }\end{array}$ & $\begin{array}{l}2 \cdot 7 \\
3 \cdot 5 \\
2 \cdot 5 \\
2 \cdot 2 \\
5 \cdot 1 \\
2 \cdot 5 \\
3 \cdot 1\end{array}$ & $\begin{array}{l}1 \cdot 9 \\
3 \cdot 5 \\
2 \cdot 4 \\
2 \cdot 1 \\
3 \cdot 1 \\
4 \cdot 5 \\
2 \cdot 9\end{array}$ & $\begin{array}{l}3 \cdot 0 \\
2 \cdot 2 \\
2 \cdot 4 \\
1 \cdot 7 \\
4 \cdot 2 \\
2 \cdot 5 \\
2 \cdot 7\end{array}$ & $\begin{array}{l}2 \cdot 1 \\
2 \cdot 2 \\
3 \cdot 5 \\
2 \cdot 2 \\
2 \cdot 9 \\
2 \cdot 1 \\
2 \cdot 5\end{array}$ \\
\hline
\end{tabular}

^Normal value $=<1 \cdot 8$.

anterior muscle of case 4 . Both legs were similarily affected with no difference between the average fibre density of the right and left leg. Jitter and blocking were seen in the majority of potential pairs recorded from the arms, especially on the affected side, but was only occasionally seen in the legs.

\section{Discussion}

Juvenile distal muscular atrophy of the upper extremities is a disorder affecting mainly males from Asia. Since its first description by Hirayama in $1959,{ }^{1}$ additional cases have been reported from Asia, including about 150 cases from Japan, ${ }^{23} 37$ cases from India ${ }^{45}$ and 102 cases from Sri Lanka. ${ }^{6}$ There is only a single report of seven Chinese cases from Malaysia. ${ }^{7}$ Sporadic cases have also been reported from Australia ${ }^{8}$ and Europe. ${ }^{10}$ The disorder has the distinctive features of male predominance, asymmetrical involvement confined to the upper extremities and a self-limiting clinical course. The clinical presentation and progression of our six Chinese men with JDSMA from Hong Kong were similar to those previously described.

Single fibre EMG fibre density measurements allow a quantitative measure of neurogenic changes in a variety of conditions such as motor neuron disease ${ }^{11}$ and syringomyelia. $^{12}$ A neurogenic aetiology for

Figure SFEMG recording. A complex potential recorded from the less affected left extensor digitorum communis muscle of patient 4. The unit is of long duration ( $20 \mathrm{~ms}$ ) with several stable components.

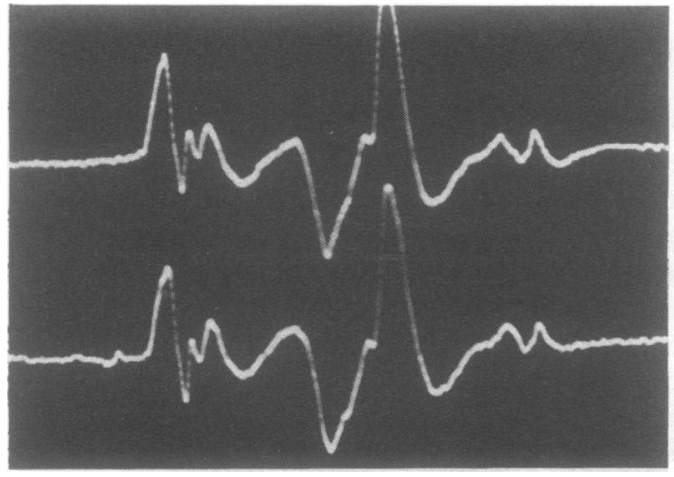

JDSMA has clearly been established by histological and EMG studies, but whether it is truly a localised disorder has not been resolved. A necropsy study showed shrinkage and necrosis of the cervical anterior horns. ${ }^{3}$ Magnetic resonance imaging also demonstrated focal atrophy of the lower cervical $\operatorname{cord}^{10}$ suggesting that the disorder was localised. Electromyography of the less affected arm shows neurogenic changes while systematic studies of the legs has rarely been reported. $^{48}$ Using SFEMG technique, our study shows that there is evidence of neurogenic changes with increased fibre density measurement in both arms and legs. Similar levels of fibre density abnormality are recorded in all extremities irrespective of the degree of clinical involvement. The only difference is the frequency of jitter and blocking which are less in the less affected arm indicating better compensatory reinnervation. In the legs, the relative lack of jitter and blocking may also explain why they are not weak. Our data provide evidence that JDSMA is a more generalised disorder than would appear clinically.

Despite the generalised electrophysiological disturbance, JDSMA should nevertheless, be separated from the other forms of motor neuron disease by its characteristic juvenile onset, male predominance, lack of clinical involvement of the lateral columns, and relatively benign self limiting clinical course.

1 Hirayama $\mathrm{K}$, Tokokura $\mathrm{Y}$, Tsubaki T. Juvenile muscular atrophy of unilateral upper extremity-a new clinical entity. Psychiatry, Neurology (Japan) 1959;61:2190-7.

2 Sobue I, Saito N, Iida M, Ando K. Juvenile type of distal and segmental muscular atrophy of upper extremities. Ann Neurol 1978;3:429-32.

3 Hirayama K, Tomonaga M, Kitano K, Yamada T, Kojima $\mathrm{S}$, Arai K. Focal cervical poliopathy causing juvenile muscular atrophy of distal upper extremity: a pathological study. J Neurol Neurosurg Psychiatry 1987;50:285-90.

4 Singh N, Sachdev KK, Susheela AK. Juvenile muscula atrophy localized to arms. Arch Neurol 1980;40:297-9.

5 Gouri-Devi M, Suresh TG, Shankar SK. Monomelic amyotrophy. Arch Neurol 1984;41:388-94.

6 Peiris JB, Seneviratne KN, Wickremasinghe HR Gunatilake SB, Gamage R. Non familial juvenile dista spinal muscular atrophy of upper extremity. $J$ Neurol Neurosurg Psychiatry 1989;52:314-9.

7 Tan CT. Juvenile muscular atrophy of upper extremity. $J$ Neurol Neurosurg Psychiatry 1985;48:285-6.

8 O'Sullivan DJ, McLeod JG. Distal chronic spinal muscular atrophy involving the hands. J Neurol Neurosurg Psychiatry 1978;41:653-8.

9 Stålberg E, Thiele B. Motor unit fibre density in extensor digitorum communis muscle. J Neurol Neurosurg Psychiatry 1975;38:874-80.

10 Biondi A, Dormont D, Weitzner I, Bouche P, Chaine P, Bories J. MR imaging of the cervical cord in juvenile amyotrophy of distal upper extremity. $A J N R$ 1989;10 263-8.

11 Schwartz MS, Swash M. Pattern of involvement in the cervical segments in the early stage of motor neuron disease: a single fibre EMG study. Acta Neurol Scand 1982;65:424-31.

12 Schwartz MS, Stålberg E, Swash M. Pattern of segmental motor involvement in syringomyelia: a single fibre EMG study. J Neurol Neurosurg Psychiatry 1980;43:150-5. 